\title{
History of Applications of Radioactive Sources in Analytical Instruments for Planetary Exploration
}

\author{
Thanasis E. Economou \\ Laboratory for Astrophysics and Space Research, Enrico Fermi Institute, \\ University of Chicago, Chicago, \\ USA
}

\section{Introduction}

Space age started with the launch of Sputnik-1 more than 50 years ago. Since then we have visited all the planets, some of them many times with very capable spacecrafts that are equipped with sophisticated payload that are returning significant information about the composition, physical condition of their surfaces and atmospheres and much more information. However, at the beginning of the space age, there were no techniques and instruments available to be used in space and had to be invented, designed, built and tested for the harsh environmental conditions in space. For the first analytical instruments in space, transuranium artificial radioisotopes produced in the national laboratories, proved to be very useful for applications in space. In early sixties Anthony Turkevich and his group at the University of Chicago applied a novel technique -- the Rutherford backscattering -- that is based on the interaction of the alpha particles with matter, to devise an instrument to obtain in-situ the chemical composition of the lunar surface [1]. In addition to measuring the backscattered alpha particles, the instrument also measures the proton energy spectra derived from the $(a, p)$ reaction of the alpha particles with some light elements in the analyzed sample. Since the bombardment of a sample with a beam of alpha particles and $x-$ rays from the same source also produces specific characteristic $x$-rays that results in additional compositional information, an additional $x$-ray detector was added to the ASI instrument to detect the produced x-rays. Based on the successful performance of this instrument on the lunar missions, more advanced and miniaturized versions complimented with an x-ray mode were developed and used in many NASA, ESA and Russian missions to several planetary bodies.

\section{The alpha scattering instrument for the lunar missions}

The technique of alpha backscattering for obtaining the chemical composition of planetary bodies was described for the first time and in detail by A. Turkevich, 1961[1], 1968[2]; Patterson et al., 1965[3]; Economou et al., 1970[4], 1973[5]. The compositional information is obtained from the energy spectra of scattered alpha particles and protons generated in $(\alpha, p)$ reactions of alpha particles with the matter in the analyzed sample. As it is shown in Fig. 1, a 
beam of monochromatic alpha particles with energy of $6.1 \mathrm{MeV}$ from ${ }^{242} \mathrm{Cm}$ alpha source is bombarding the sample to be analyzed. The resulting scattered alpha particles and protons from $(\alpha, p)$ reactions are detected by solid state Si detectors situated as close to $180^{\circ}$ as possible for maximum separation of individual elements. The energy of scattered alpha particles depends mostly on the scattered angle and the mass of the nucleus A, from which it is scattered. The sensor head of the Alpha Scattering Instrument (ASI) containing all the detectors, sources and the first stages of the electronic preamplifiers is deployed to the surface of the Moon and it is exposed to the harsh lunar environmental conditions, as it is shown in Fig. 2. The rest of the ASI electronics is placed inside the spacecraft compartment that is more controlled for temperature extremes.

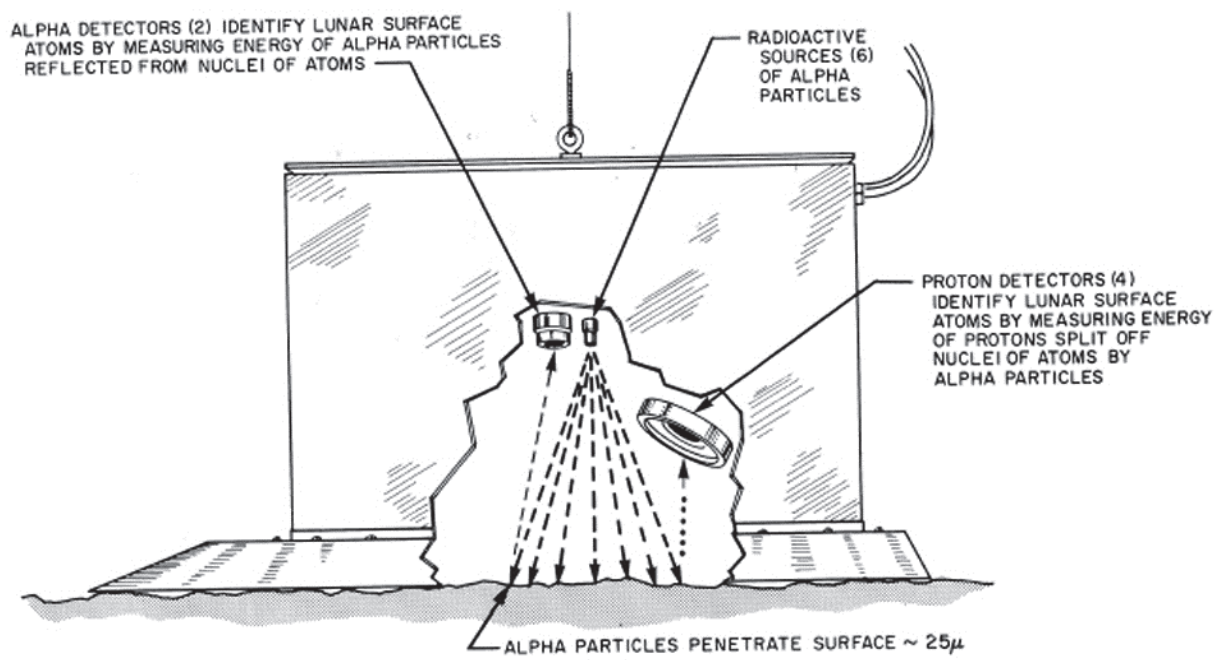

Fig. 1. The Alpha Scattering Instrument sensor head [2] 


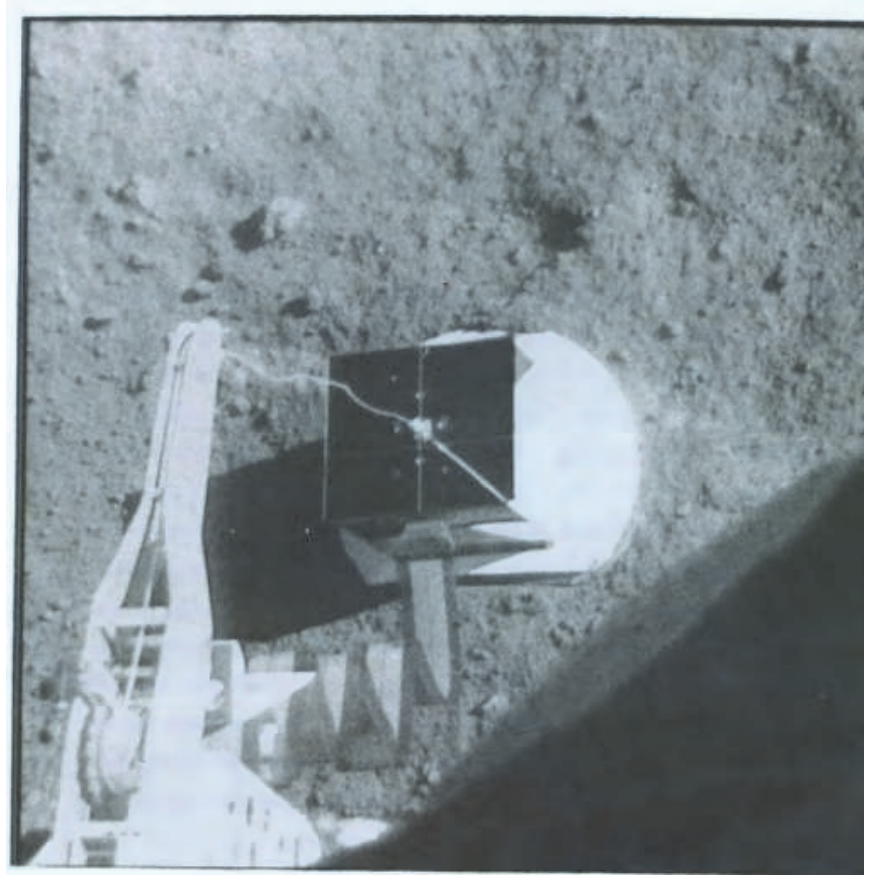

Fig. 2. The Alpha Scattering instrument deployed on the surface of the Moon

The energy $\mathrm{E}$ of scattered alpha particles in respect to its initial energy $\mathrm{E}_{0}$ is a function of scattering angle $\theta$ and the mass $\mathrm{A}$, of the target atom.

$$
\frac{E}{E_{0}}=\left(\frac{4 \cos \Theta+\left(A^{2}-16 \sin ^{2} \Theta\right)^{1 / 2}}{A+4}\right)^{2}
$$

Which for $\theta=180^{\circ}$ converts to

$$
\frac{E}{E_{0}}=\left(\frac{A-4}{A+4}\right)^{2}
$$

Since we know the initial source energy, $E_{0}$, the mass $A$, from which an alpha particle is scattered, can be calculated from the measured energy $\mathrm{E}$ from the above equation. For the Surveyor lunar missions in the 1960's the ASI used several hundred millicuries of ${ }^{242} \mathrm{Cm}$ alpha particle source of $6.1 \mathrm{MeV}$. Figure 3 shows some alpha spectra from pure elements and the alpha and proton spectra from lunar samples from the Surveyor 7 lunar mission. From these spectra, the elemental composition of the lunar surface material has been derived. The ASI on three Surveyor series lunar missions in 1967-68 provided the first detailed and complete elemental composition of the lunar surface. The comparison of the lunar analyses results provided by the ASI on the Surveyor 5 and Surveyor 7 with those analyses of lunar material brought back from the Moon by the Apollo 11 astronauts is shown in Fig. 4 [6]. 


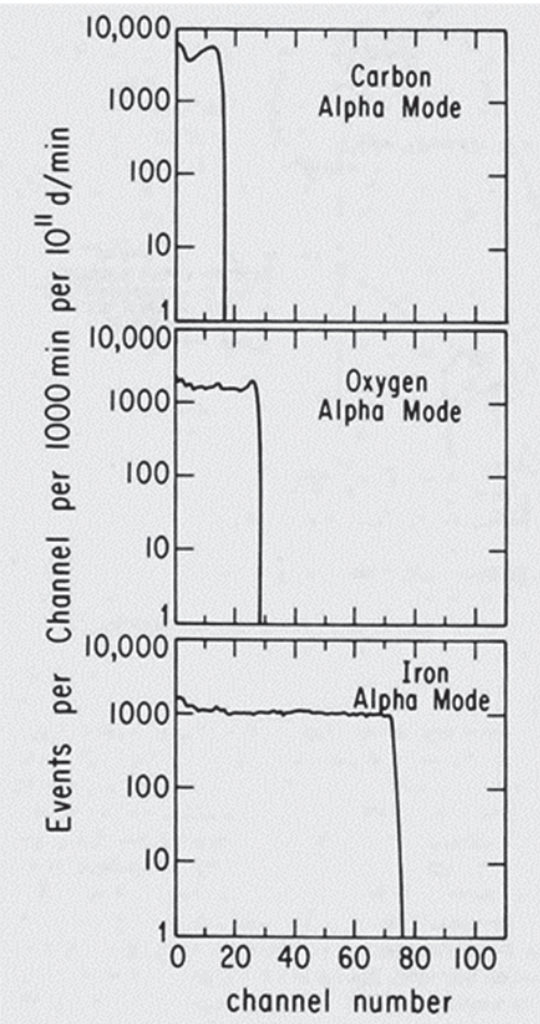

a

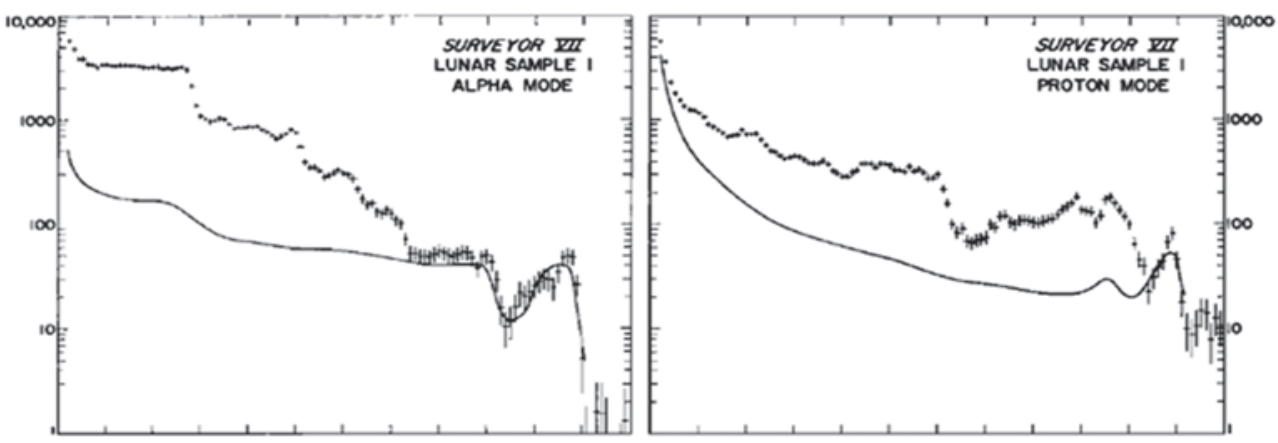

$\mathrm{b}$

Fig. 3. a: Alpha spectra from carbon, oxygen and iron, b: ASI alpha and proton spectra from Lunar sample 1 of Surveyor 7.

This experiment was credited as the beginning of the Alpha Backscattering Spectroscopy (ABS) which has become a common analytical technique in many terrestrial laboratories. The ABS is using, however, a beam of alpha particles from a particle accelerator instead from radioisotopes. 


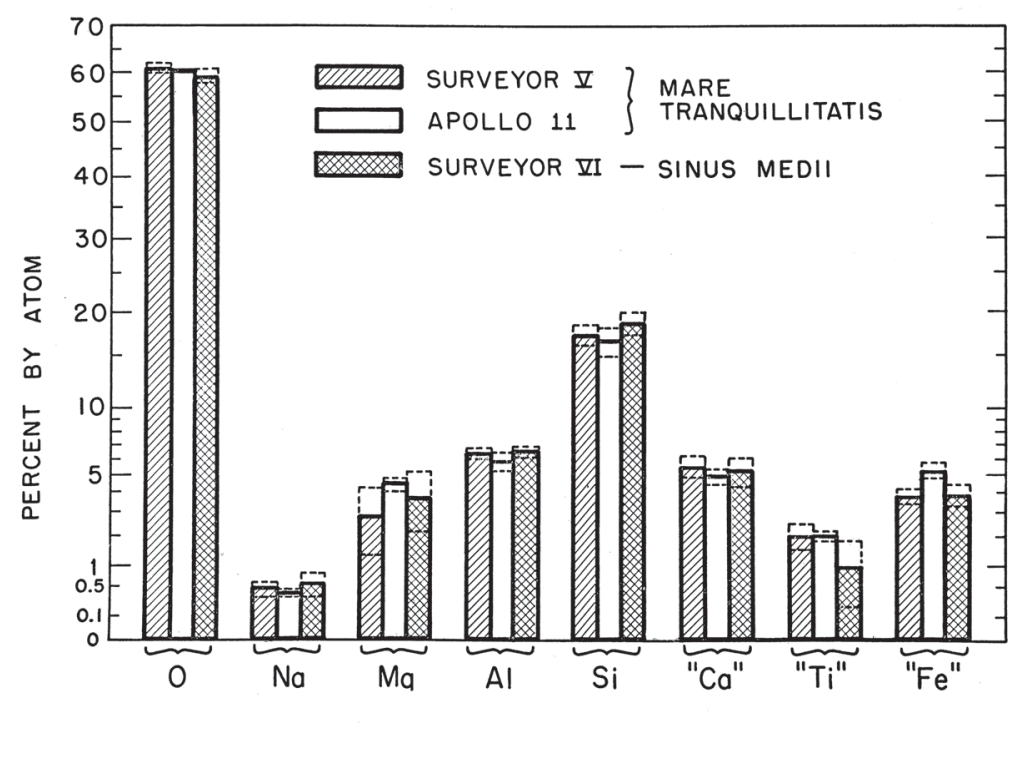

Fig. 4. Comparison of the ASI Surveyor 5 and Surveyor 7 results of the chemical composition of lunar surface material with those brought back by the Apollo 11 astronauts.

\subsection{The ${ }^{242} \mathrm{Cm}$ alpha sources}

The Alpha Scattering Instrument on the Surveyor lunar missions that provided the first chemical analysis of lunar material required alpha particle sources of high intensity and quality. In choosing the right isotope several criteria had to be taken into consideration. The decay half-live time has to be short in order to have essentially weightless sources, but long enough so that the sources will not decay appreciably before the completion of the measurements. Also, the source had to emit monoenergetic alpha particles with energy as high as possible and any decay daughter products should grow very slowly.

It was found that ${ }^{242} \mathrm{Cm}$ isotope $\left(\mathrm{T}_{1 / 2}=163\right.$ days, $\left.\mathrm{E}_{\alpha}=6.11 \mathrm{MeV}\right)$ fits all the criteria best. This isotope emits essentially monoenergetic alpha particles and the decay half-life time of its daughter product ${ }^{238} \mathrm{Pu}$ is $86 \mathrm{yrs}$. So, it was ideal for the short missions to the Moon.

The procedure of preparing ${ }^{242} \mathrm{Cm}$ is long and complicated and it is described in details by Paterson et al., [7]. It starts with irradiation of ${ }^{241} \mathrm{Am}$ with neutrons in nuclear reactors which converts it to ${ }^{242} \mathrm{Am}$ by neutron capture followed by EC decay into ${ }^{242} \mathrm{Cm}$ and ${ }^{242} \mathrm{Pu}$. After that, substantial purification yielded pure ${ }^{242} \mathrm{Cm}$ that was deposited on stainless steel plates of an active area of $2.8 \mathrm{~mm}$ in diameter and loaded into the ASI instrument.

Although ${ }^{241} \mathrm{Am}$ is wildly abundant because it is the decay product of reactor produced ${ }^{241} \mathrm{Pu}$, the availability of ${ }^{242} \mathrm{Cm}$ is very scarce, especially in large quantities, due to its short half-life time. For the Surveyor lunar missions, a special program supported by the Atomic Energy Commission was undertaken at Argonne National Laboratory to produce adequate quantities of ${ }^{242} \mathrm{Cm}$ alpha sources with high qualities required for the experiment. Table 1 lists the main source characteristics of ${ }^{242} \mathrm{Cm}$ alpha sources used in the ASI on the Surveyor lunar missions in the late 1960's. 


\begin{tabular}{|l|l|}
\hline Radioisotope & $242 \mathrm{Cm}$ \\
\hline Number of Sources & 6 \\
\hline Total Intensity & $\mathbf{1 2 0 - 4 7 0}$ millicuries \\
\hline $\mathbf{E}_{\boldsymbol{a}}$ & $\mathbf{6 . 1 1 \mathrm { MeV }}$ \\
\hline $\mathbf{T}_{1 / 2}$ & $\mathbf{1 6 2 . 8 \mathrm { days }}$ \\
\hline \hline FWHM & $\mathbf{1 . 5 - 1 . 9} \%$ \\
\hline FW0.1M & $\mathbf{2 . 5 - 3 . 0 \%}$ \\
\hline FW0.01M & $\mathbf{5 . 0 - 8 . 0 \%}$ \\
\hline
\end{tabular}

Table 1. Characteristics of the ${ }^{242} \mathrm{Cm}$ alpha radioactive source used in the ASI instrument on the Surveyor 5-7 missions to the Moon.

\subsection{The "Mini-Alpha" alpha proton X-ray spectrometer (APXS)}

Most of the alpha emitting radioisotopes, beside emitting alpha particles, also emit x-rays in the energy range $14-20 \mathrm{keV}$ and some gamma rays that are useful in exciting with different efficiency the characteristic XRF lines from every element. The higher $Z$ elements are more efficiently excited by the X-ray lines emitted by the Curium isotopes alpha sources, while the lower $\mathrm{Z}$ elements are better excited by the alpha particles of 5-6 MeV (see Fig. 5a). These generated $x$-rays contain additional compositional information and were used to dramatically improve the analytical information of the ASI instrument, extending the performance to the presence of minor elements down to several tens of ppm range. On the other hand, the alpha mode is capable of better separating the light elements, while the $x$-ray mode has a better separation resolution for the heavier $Z$ elements (see Fig. 5b). Therefore, an additional mode has been added to the original ASI instrument to detect the resulting characteristic $x$-rays that are produced when a sample is bombarded with a beam of alpha particles and x-rays from the same radioactive source. It is the combination of all three modes, the Rutherford alpha backscattering, the $\mathrm{x}$-ray fluorescence (XRF) and the particle PIXE techniques that resulted in one integrated low power, low volume, but very powerful Alpha Proton X-ray Spectrometer (APXS) analytical instrument [8] that has been used in so many space missions [9-20].

A refined and miniaturized instrument with alpha, proton and x-ray modes (the "AlphaProton X-ray Spectrometer by Economou et al., 1976[8]) was proposed for analysis of Martian surface material during preparation for the Viking missions, but it was not selected for that mission. But the development of the "Mini-Alpha" APXS instrument was essential for future missions to Mars and other planetary bodies.

Figure 6 shows the diagram of the "Mini-Alpha" instrument. Its sensor head contains two telescopes with a combination of a thin $\mathrm{dE} / \mathrm{dx}$ and thicker Si solid state detectors for the alpha and proton modes and a separate $\mathrm{x}$-ray detector for the $\mathrm{x}$-ray mode. The big challenge of miniaturization and enabling the use of such an instrument for space missions was the requirement of a good energy resolution for the x-ray detector. In the terrestrial laboratories every $\mathrm{x}$-ray detector is kept at very low temperatures by cooling it with liquid nitrogen, which is for space application prohibitive. An enormous effort was undertaken to replace the Si-cooled x-ray detector with one that can operate at ambient Mars environment. Varieties of detectors made from exotic materials like $\mathrm{Ge}, \mathrm{HgI}_{2}, \mathrm{CdTe}, \mathrm{CdZn}$ and other materials were tried with a different degree of success. Finally, we used a Si PIN detector that could provide sufficient energy resolution at martian ambient temperatures, and space qualify it at the last moment for the Pathfinder missions to Mars in 1996. 


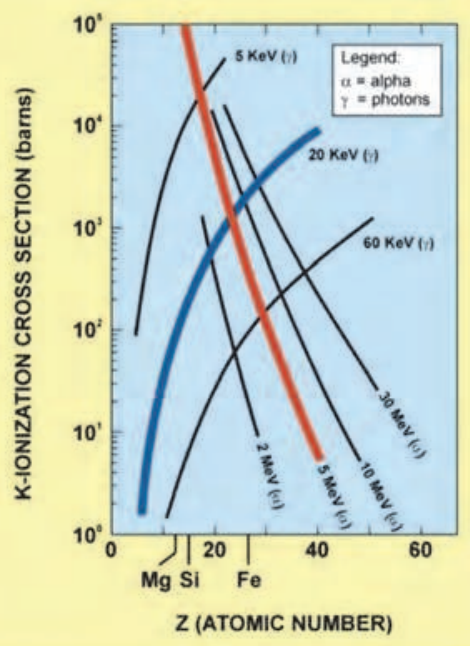

Fig. 5a. The characteristic X-rays are the result of two different mechanisms: X-ray fluorescence (in this particular case by the Pu L- lines in the $14-20 \mathrm{keV}$ range) which is most effective for high $\mathrm{Z}$ elements and by particle induced $\mathrm{X}$-ray emission (PIXE) that is most effective for the low $\mathrm{Z}$ elements.

\section{RBS versus X-RAY, Selectivity}

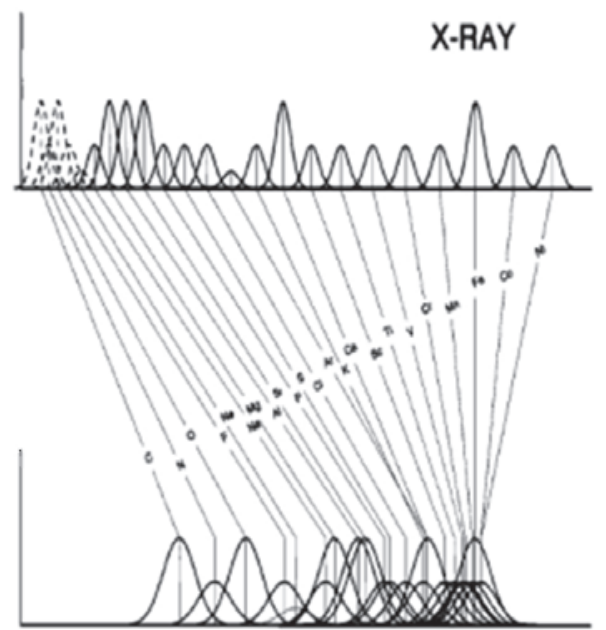

ALPHA-RBS

Fig. 5b. The X-ray mode of the APXS separates better the heavier Z elements while the alpha mode has much better resolution power for the light elements. The combination of these two modes makes the APXS a very powerful analytical instrument. 


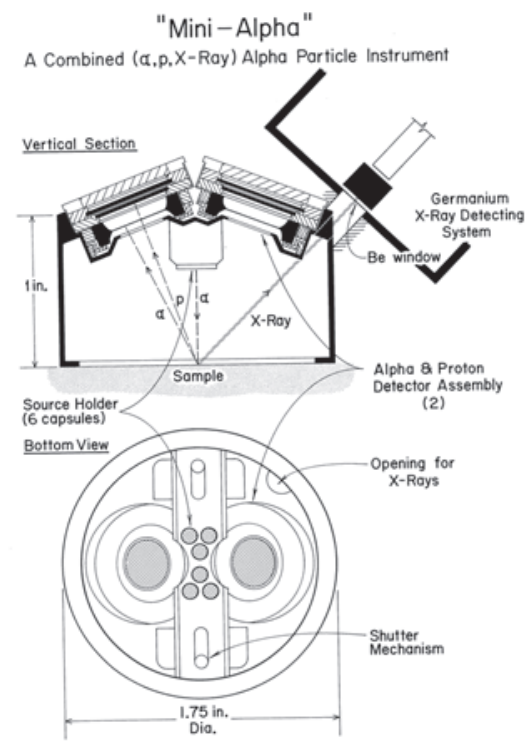

Fig. 6. An Alpha Proton X-ray Spectrometer "Mini-alpha" combining the alpha, proton and xray modes in one low power, low volume but high performance analytical instrument on basis of which several version have been used in many planetary missions. The big challenge was to replace the LN cooled x-ray detector with one able to operate at the ambient temperatures.

Based on the "Mini-Alpha" instrument several APXS instruments have been proposed and selected for the following space missions:

1. Soviet Phobos 1 and Phobos 2 missions to martian satellite Phobos in 1988.

2. Russian Mars-96 mission to Mars in 1994 (1996)

3. Pathfinder NASA mission to Mars in 1996

4. ESA's Rosetta mission to Comet Cheryumov-Gerasimenko in 2002

5. APXS on NASA Mars Exploration Rover missions (Spirit and Opportunity) in 2003

6. APXS on NASA Mars Science Laboratory in 2011.

\section{Mars pathfinder alpha proton X-ray spectrometer (APXS)}

The Alpha Proton X-ray Spectrometer (APXS) for the Mars Pathfinder mission in 1996 [12] was based on the design of the "Mini-Alpha" APXS [8] and used about 45 millicuries of ${ }^{244} \mathrm{Cm}$ alpha source instead the previously used ${ }^{242} \mathrm{Cm}$ isotope. Fig.7 is a photograph of the Pathfinder APXS flight instrument. It consists of two parts: 1/ the sensor head containing nine ${ }^{244} \mathrm{Cm}$ alpha sources in a ring-type geometry and three detectors for the measurement of the three components: A telescope of two Si-detectors for the measurement of alphaparticles and protons and a Si-PIN X-ray detector with its preamplifier, and 2 / the main electronic box that contains all the necessary electronic components of a spectrometer and its interface with the spacecraft. The total weight of the Pathfinder APXS is 570 grams and it needed only $370 \mathrm{mWatts}$ of power for its operation. The sensor head of the APXS is mounted in rear of the Sojourner microrover and it is deployed to the surface by its deployment mechanism as it is shown in Figure 8. 
The Mars Pathfinder APXS performed very well on Mars and provided us for the first time the chemical composition of martian rocks [13-15]. It was also found that the soil chemical composition was very similar to that found by Viking XRF spectrometer in 1976[15].

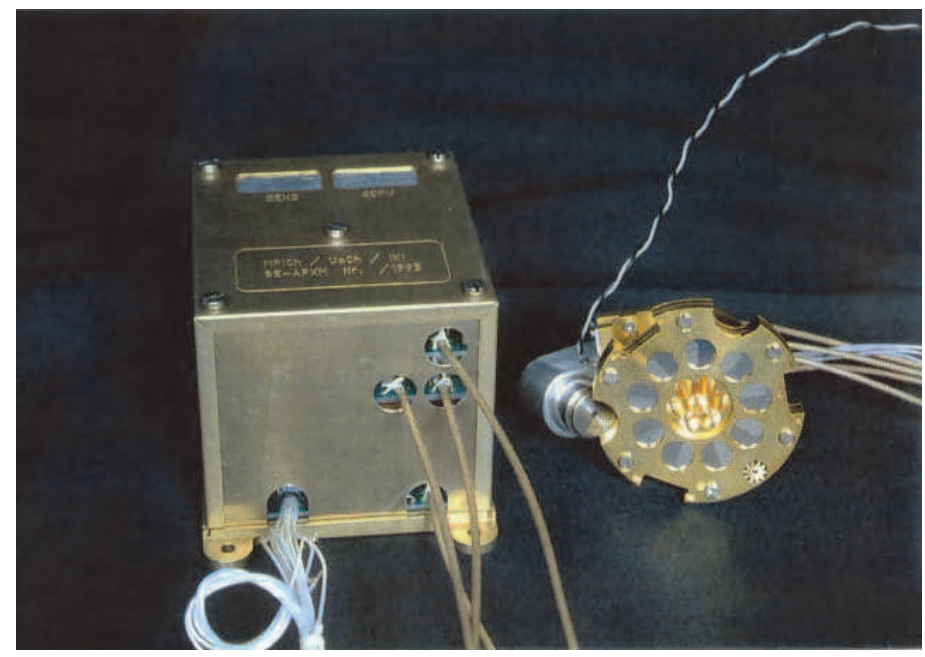

Fig. 7. A photograph of the Pathfinder APXS flight instrument

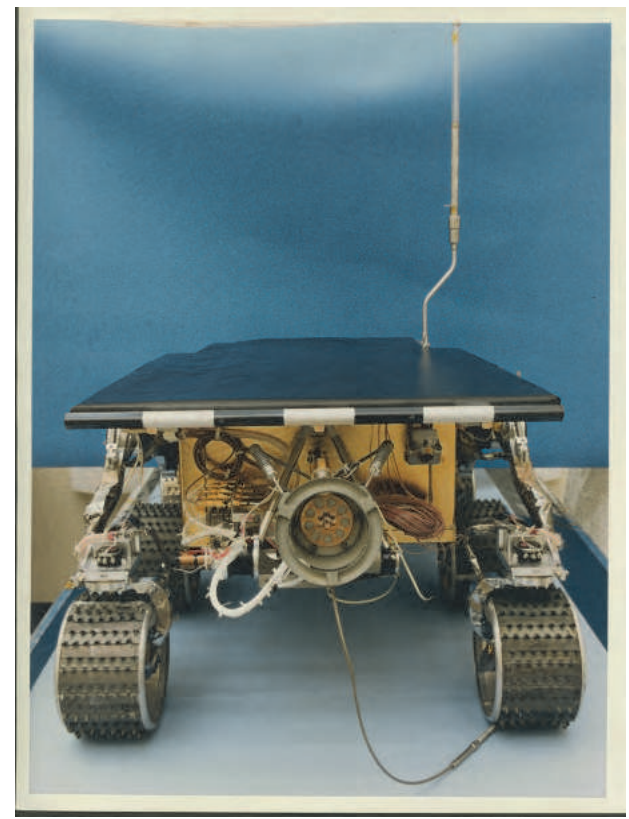

Fig. 8. APXS is mounted on the rear of Sojourner microrover and it is deployed to the surface by its own deployment mechanism. 


\subsection{Cm-244 alpha sources}

For longer mission to distant planetary bodies, ${ }^{242} \mathrm{Cm}$ has too short a half-life decay time (163 days) and it would be too weak by the time the spacecraft reaches the target planets. ${ }^{244} \mathrm{Cm}$ with a half-life time of 18.1 years and $E_{\mathrm{a}}=5.8 \mathrm{MeV}$ seems to be a much better choice for such missions because it has similar characteristics of $242 \mathrm{Cm}$ but has a much longer half-life time. The disadvantage of a longer half-life isotope is that for the same intensity one must pack more radioactive material per unit area, which deteriorates the energy resolution of the source by self absorption in its thickness of the material. Earlier, the ${ }^{244} \mathrm{Cm}$ was readily available in the US from the Livermore National Laboratory, but presently it is available only from the State Scientific Centre Research Institute of Atomic Reactors Dimitrovgrad, Russia.[21] There, the sources are prepared by high temperature condensation of metal curium vapor onto silicon substrates. For source production, the initial fraction of ${ }^{244} \mathrm{Cm}$ content was about $93 \%$. Then, before the stage of source preparation, the curium was purified from daughter ${ }^{240} \mathrm{Pu}$ nuclide and additionally purified from americium, microquantities of ${ }^{252} \mathrm{Cf}$ and other impurities. The final deposition was on the silicon disks with ${ }^{244} \mathrm{Cm}$ fixed on their surfaces as a silicide. The sources for the Mars Pathfinder mission have overall dimensions as follows: disk diameter 8 $\mathrm{mm}$; thickness $0.3 \mathrm{~mm}$; and $6 \mathrm{~mm}$ diameter active spot. The source activities are $5 \pm 1 \mathrm{mCi}$ and the alpha-line half-widths are equal to (1.7-2.5) and (2.9-4.5)\% of full width at half maximum energy of $5.8 \mathrm{MeV}$. The sources and their spectral characteristics stability were studied at wide intervals of physical and chemical parameters of the environment simulating real conditions of storage and maintenance. Thermo-vacuum (from $-60^{\circ} \mathrm{C}$ up to $1000{ }^{\circ} \mathrm{C}$ ), mechanical, and vibrational tests were performed to demonstrate that the sources maintained their characteristics. Table 2 lists the main characteristics of the alpha sources used for the Pathfinder APXS instrument.

\begin{tabular}{|l|l|}
\hline Radioisotope & $244 \mathrm{Cm}$ \\
\hline \hline Number of Sources & 9 \\
\hline \hline Total Intensity & 50 millicuries (1.85*109 Becq.) \\
\hline \hline Ea & $5.807 \mathrm{MeV}$ \\
\hline \hline $\mathrm{T}_{1 / 2}$ & $\mathbf{1 8 . 1}$ years \\
\hline \hline FWHM & $\mathbf{2 . 3} \%$ \\
\hline \hline FW0.1M & $\mathbf{3 . 5 \%}$ \\
\hline \hline FW0.01M & $\mathbf{1 0 . 0} \%$ \\
\hline \hline
\end{tabular}

Table 2. Characteristics of the ${ }^{244} \mathrm{Cm}$ alpha radioactive source used for the Mars Pathfinder APXS instrument.

Also, an important factor in determining the resulting energy spread of a source is the chemical composition of the source material: the ideal case is to use the source material in elemental form. In the case of curium, however, the metal becomes chemically unstable and the sources deteriorate rapidly. More recent work [21] concentrated on the formation of curium silicides on the surface of semiconductor grade silicon. This technology has yielded the best results so far and sources for the current or future APXS instruments will be produced by this technique. 
The ${ }^{242} \mathrm{Cm}$ and ${ }^{244} \mathrm{Cm}$ alpha sources as used for the lunar and earlier Mars missions are called "open" alpha sources without any cover in order not to degrade the energy resolution of the alpha sources, which is one of the requirements for a good alpha spectrometer. However, using "open" sources present some challenges in handling radioactive sources and preventing source contamination of the spectrometer and its environment. During the fission decay, some recoil product can get out of the source housing and contaminate the instrument and the targets as well. In these cases, a very thin film of $\mathrm{Al}_{2} \mathrm{O}_{3}$ and VYNS (polypropylene) combination of a total thickness of $1200 \AA$ was used in front of the source collimators. This thickness did not not affect the energy resolution of the alpha particles much but it is thick enough to stop the recoil products and prevent any contamination.

For the most recent APXS, the $244 \mathrm{Cm}$ are placed in a sealed housing covered with a thin 2 micron $\mathrm{Ti}$ foil. This somewhat degrades the alpha source energy resolution, however without degrading significantly the analytical performance of the APXS. First, for convenience, aluminum foils have been used for that purpose, but their use was discontinued when it was realized that the aluminum is easily oxidizing in the air with time causing continuous decreasing of the energy of the alpha particles.

The big advantage of sealed alpha sources is in much easier handling of the radioactive sources, easier way to prevent source contamination, but mainly it makes the transportation of radioactive material much easier and without a requirement for a special transport containers approved by the IAEA.

\section{The Mars exploration rover APXS}

For the Mars Rover Exploration (MER) mission in 2003 a more advanced x-ray sensor was developed which uses a silicon drift $x$-ray detector with a 5 - $\mu$ m beryllium entrance window and has an energy resolution of about $155 \mathrm{eV}$ at $5.49 \mathrm{keV}$ that rivals the energy resolution of the best terrestrial XRF laboratory spectrometers [16]. The rest of the APXS is almost similar to the one used on the Pathfinder. The sensor head of the APXS that contains the alpha sources and all the detectors together with the first stage of amplification electronics was mounted on the Instrument Deployment Device (IDD) of the MER rovers Spirit and Opportunity (robotic arm) and could be deployed to any selected target on the martian surface in sequence with other analytical instruments on the robotic arm, as can be seen in Fig. 9. The rest of the APXS electronics is located inside the temperature controlled compartment of the rover.

The APXS on the MER mission performed very well throughout the entire mission. Although the MER mission was designed to operate only for 3 months on the surface of Mars, we are now still operating successfully after 7 years on the surface of Mars without any degradation in its performance. Actually, due to the decay of radioactive sources used on Mössbauer instrument that was raising the APXS background, the signal to noise ratio in the APXS is better now, 7 years later in the mission, rather than at the beginning of the MER mission in 2004.

Fig. 10 shows the spectra obtained by the APXS on Mars Explorer mission of soil on two different landing sites, on Meridiani planum and Gusev crater. As it can be seen from the spectra, except for some small differences, the soil composition on both sites is very similar. The APXS has analyzed hundreds of martian samples and found many different lithologies, starting with basalt-like rocks, altered basalts, to rocks containing large amount sulfur, phosphor, magnesium, etc., on both landing sites. One such lithology with almost half of the sample in the form of sulfates is shown in Figure 11. 


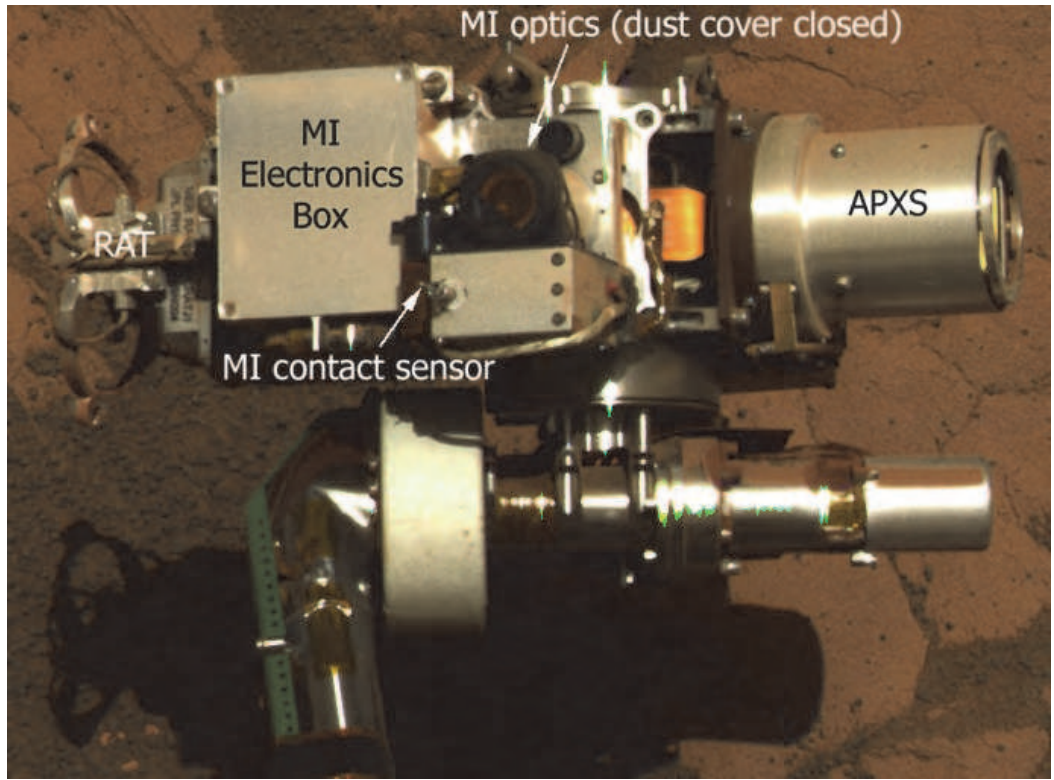

Fig. 9. The Instrument Deployment Device (IDD) of the MER rovers Spirit and Opportunity (robotic arm) showing the mounting of the APXS. The deployment of the APXS to the surface is done by commanding whenever it is desirable.

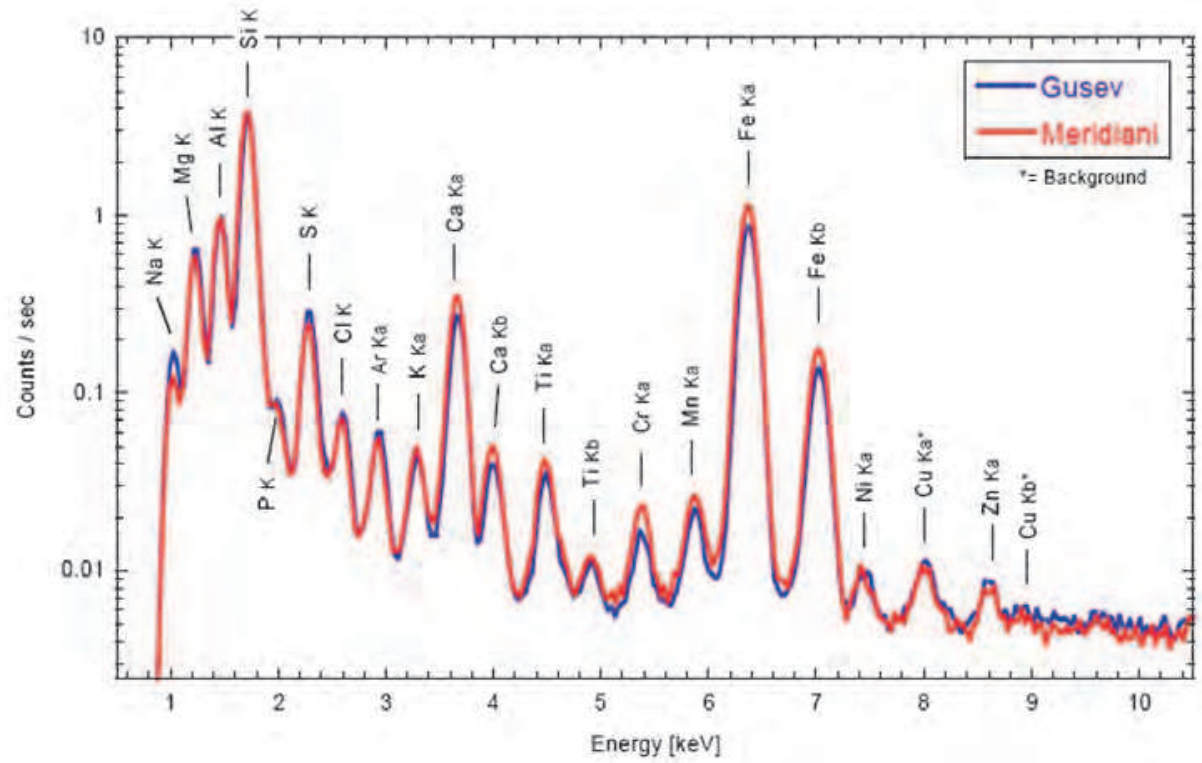

Fig. 10. APXS X-ray spectra of Martian soils measured at Gusev Crater (blue) and Meridiani Planum (red). 


\begin{tabular}{|l|l|}
\hline Sample Name: & A401_sulf_soil \\
\hline Spacecraft: & MER2 \\
\hline Sol \#: & 401 \\
\hline Measurement Start (LST): & $05: 58: 54$ \\
\hline Measurement Duration: & $6: 50: 10$ \\
\hline DAT.-file \#: & 2A161961338EDRA600N1438N0M1 \\
\hline LBL.-file \#: & 2A161961338EDRA600N1438NOM1 \\
\hline Time created: & 2005-02-19 06:59:26 \\
\hline
\end{tabular}

\begin{tabular}{|l|c|}
\hline $\mathrm{Fe}^{2+} / \mathrm{Fe}_{\text {tot }}$ from MB: & 0.7 \\
\hline Relative Geometric Yield : & 0.85 \\
\hline Ratio of Pu-L $\alpha$ scatter lines (coh/incoh): & 0.62 \\
\hline Intensity of Pu-L $\alpha$ coh. scatter line (cps): & 0.40 \\
\hline Geometric Yield from scatter lines: & 0.67 \\
\hline
\end{tabular}

\begin{tabular}{|l|c|c|c|}
\hline Ratios: & $\mathrm{Mg} / \mathrm{Si}$ & $\mathrm{Al} / \mathrm{Si}$ & $\mathrm{FeO} / \mathrm{MgO}^{(4)}$ \\
\hline by wt & 0.43 & 0.29 & 3.00 \\
\hline
\end{tabular}

\section{APXS Preliminary Analysis}

\begin{tabular}{|c|c|c|c|c|}
\hline Elements & wt\% & Oxides & wt\% & $\mathrm{mol} \%$ \\
\hline $\mathrm{Na}^{(3)}$ & 1.60 & $\mathrm{Na}_{2} \mathrm{O}$ & 2.20 & 2.60 \\
\hline $\mathrm{Mg}$ & 4.00 & $\mathrm{MgO}$ & 6.60 & 11.90 \\
\hline Al & 2.70 & $\mathrm{Al}_{2} \mathrm{O}_{3}$ & 5.10 & 3.60 \\
\hline $\mathrm{Si}$ & 9.20 & $\mathrm{SiO}_{2}$ & 19.70 & 23.90 \\
\hline $\mathbf{P}$ & 2.53 & $\mathrm{P}_{2} \mathrm{O}_{5}$ & 5.80 & 2.97 \\
\hline$S$ & 12.30 & $\mathrm{SO}_{3}$ & 30.70 & 27.90 \\
\hline $\mathrm{Cl}$ & 0.45 & $\mathrm{Cl}$ & 0.45 & 0.90 \\
\hline K & 0.07 & $\mathrm{~K}_{2} \mathrm{O}$ & 0.09 & 0.07 \\
\hline $\mathrm{Ca}$ & 4.60 & $\mathrm{CaO}$ & 6.40 & 8.30 \\
\hline $\mathrm{Ti}$ & 0.27 & $\mathrm{TiO}_{2}$ & 0.44 & 0.40 \\
\hline $\mathrm{Cr}$ & 0.04 & $\mathrm{Cr}_{2} \mathrm{O}_{3}$ & 0.05 & 0.02 \\
\hline $\mathrm{Mn}$ & 0.17 & $\mathrm{MnO}$ & 0.21 & 0.22 \\
\hline $\mathrm{Fe}$ & 15.50 & $(\mathrm{FeO})^{(2)}$ & 14.00 & 14.10 \\
\hline $\mathrm{Ni}(\mathrm{ppm})$ & 70 & $\left(\mathrm{Fe}_{2} \mathrm{O}_{3}\right)^{(2)}$ & 6.60 & 3.00 \\
\hline Zn (ppm) & 90 & $\mathrm{Fe}_{2} \mathrm{O}_{3} \mathrm{~T}$ & 22.20 & \\
\hline $\mathrm{Br}(\mathrm{ppm})$ & 460 & $\Sigma$ Oxides $^{(1)}$ & 99.9 & 100.0 \\
\hline
\end{tabular}

Notes:

(1) sample matrix (for matrix correction and geometric yield) by closure, assuming all $\mathrm{Fe}$ as $\mathrm{Fe}_{2} \mathrm{O}_{3}$, and matrix free of $\mathrm{H}_{2} \mathrm{O}, \mathrm{CO}_{2}$, etc.

(2) calculated with $\mathrm{Fe}^{2+} / \mathrm{Fe}_{\text {tot }}$ from MB (default assumption: $\mathrm{Fe}^{2+} / \mathrm{Fe}_{\text {tot }}=0.7$ ).

(3) $\mathrm{Na}$ too low (by $~ 30 \%$ ) due to faulty algorithm. Will be corrected asap.

(4) assumes all $\mathrm{Fe}$ as $\mathrm{FeO}$

Fig. 11. The chemical analyses results from a soil sample A_0401, obtained by the APXS on Spirit on Martian sol 401 showing very high concentration of sulfates. 


\section{The nano alpha-X instrument for MUSES-C mission}

In the year of 2000, NASA, with collaboration with Japanese JAXA, were getting ready for the MUSES-C mission to bring back to Earth a sample from an asteroid. On that mission, it was also proposed to study in-situ the surface characteristics of that asteroid with a nanorover populated with several analytical instruments, including an Alpha-X Spectrometer (AXS) [22] to obtain the chemical composition of the asteroid surface material. For that mission, a further miniaturization of the AXS was required to fit it inside the Jet Propulsion Laboratory's nanorover with the overall dimensions of $14 \times 15 \times 6 \mathrm{~cm}$. A massive hybridization and elimination of the proton mode resulted in a miniaturized Alpha- $X$ Spectrometer shown in Fig. 12 and with specifications listed in Table 3. The AXS, although drastically miniaturized, is a complete spectrometer capable of providing highly accurate analytical results, similar to other APXS instruments.

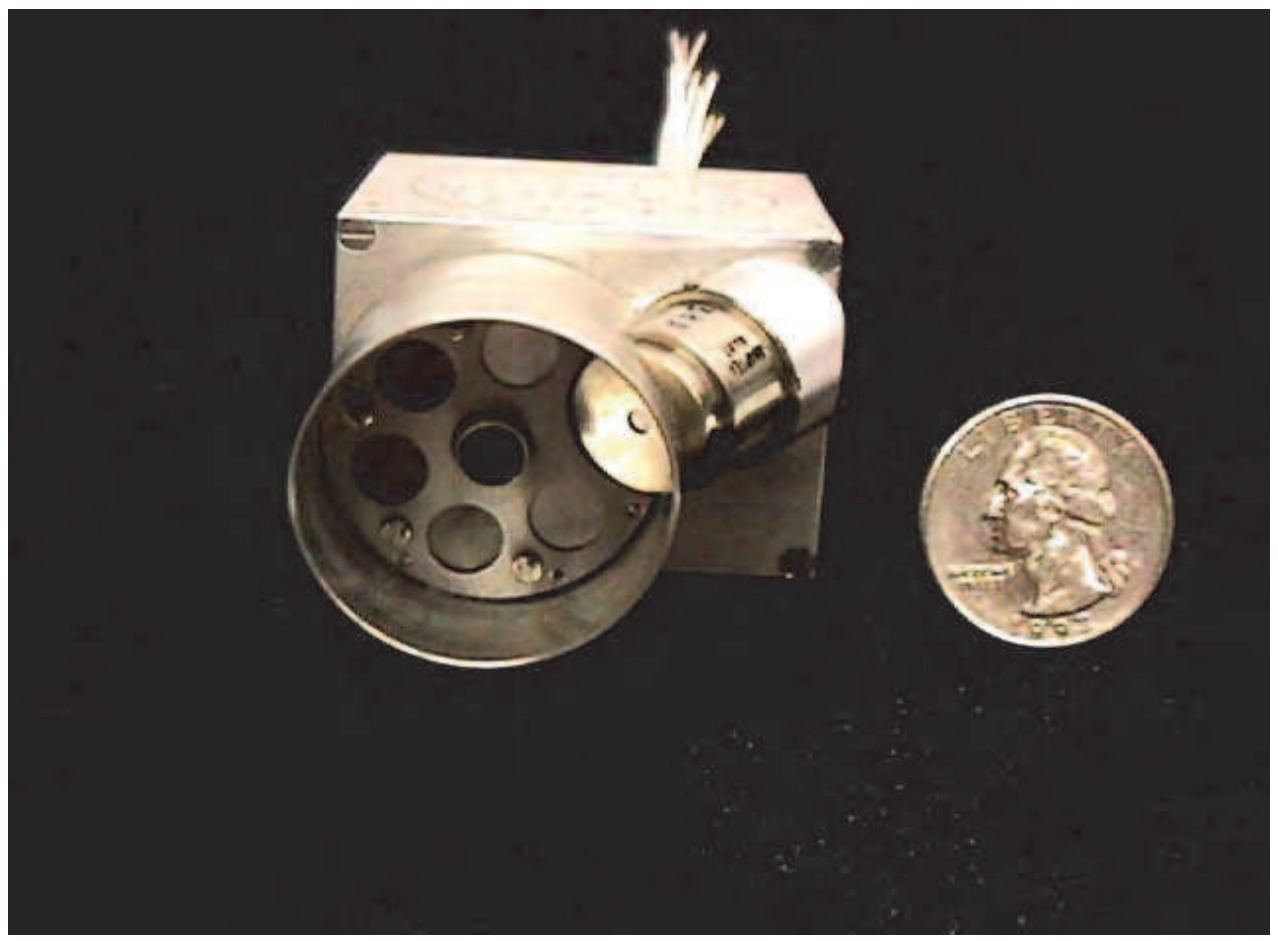

Fig. 12. A photograph of AXS laboratory instrument for MUSES-C mission. 


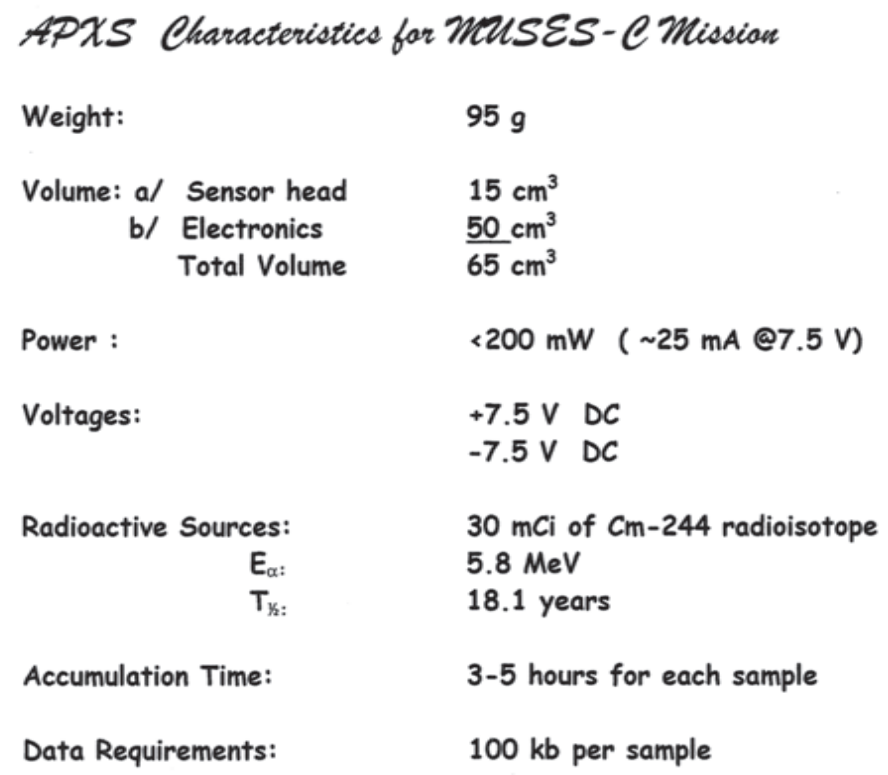

Table 3. Characteristics of the AXS instrument for MUSES-C mission. 
The MUSES-C mission suffered several long delays and NASA eventually cancelled its participation on this mission. The Japanese, however, went ahead with the mission that was renamed Hayabusa after the launch in 2003 and succeeded in bringing back a small amount of asteroid material from asteroid Itokawa in June, 2010. Despite the cancellation, the AXS was designed, built and fully flight qualified. It is now available for some potential future mission.

\section{Summary}

We have described here some of the techniques and analytical instruments that have been developed in the past half century and used for space applications. Many other space analytical instruments have used radioactive sources in one way or another that have not been described here. Some of the developed techniques had a profound influence in developing analytical instruments that are used today in many terrestrial laboratories around the world.

Table 4 shows some of the radioisotopes used in different analytical instruments on space missions. Besides the ${ }^{242} \mathrm{Cm}$ and ${ }^{244} \mathrm{Cm}$ that were used in the APXS, the Mössbauer experiment on the MER mission used about 400 millicuries of ${ }^{57} \mathrm{Co}$ at the start of the mission, to obtain the mineralogy of the iron bearing rocks [10]. Similarly, ${ }^{55} \mathrm{Fe}$ has been used in an XRF instrument on Viking mission in 1976 [11] and on the Beagle 2 mission in 2003 [12].

\begin{tabular}{|l|l|l|l|l|}
\hline & Isotope & $\begin{array}{l}\text { Half Live } \\
\text { Time }\end{array}$ & $\begin{array}{l}\text { Energy, } \\
\text { Type }\end{array}$ & Space Mission \\
\hline 1. & Cm-242 & 161 days & $6.1 \mathrm{MeV}, \mathrm{a}$ & ASI Surveyor Lunar Missions, 1967-1968 \\
\hline 2. & $\mathrm{Cm}-244$ & 18.1 years & $5.8 \mathrm{MeV}, \mathrm{a}$ & $\begin{array}{l}\text { Phobos1@2('88), Mars96('96), } \\
\text { Pathfinder('97), } \\
\text { MER(2004), MSL(2011), Rosetta (2002) }\end{array}$ \\
\hline 3. & Fe-55 & $2.7 \mathrm{y}$ & $5.9 \mathrm{keV,x}$ & Viking 1\&2 (1976), Beagle 2 (2003) \\
\hline 4. & Co-57 & 271 days & $\begin{array}{l}14,122 \mathrm{keV}, \\
\mathrm{Y}\end{array}$ & Viking 1\&2 (1976), MER (2004) \\
\hline 5. & Am-241 & $432 \mathrm{y}$ & $\begin{array}{l}5.49 \\
\mathrm{MeV}, \mathrm{a}, \mathrm{\gamma}\end{array}$ & XRF \\
\hline 6. & Pu-238 & $87.74 \mathrm{y}$ & $5.5 \mathrm{MeV}, \mathrm{a}$ & $\begin{array}{l}\text { Radioisotope Thermoelectric Generators } \\
\text { (RTG), Radioactive Heating Units (RHU), } \\
\text { many space missions }\end{array}$ \\
\hline 7. & Pu-239 & $2.4 \times 104 \mathrm{y}$ & $5.15 \mathrm{MeV}, \mathrm{a}$ & Calibrations \\
\hline
\end{tabular}

Table 4. The most common radioisotopes used in the analytical instrument for space applications 


\section{References}

[1] Turkevich, A., "Chemical analysis of surfaces by use of large-angle scattering of heavy charged particles", Science, 134, 672, 1961.

[2] A. L. Turkevich, W. A. Anderson, T. E. Economou, E. J. Franzgrote, H. E. Griffin, S. L. Crotch, J. H. Patterson and K. P. Sowinski. "The Alpha-Scattering Chemical Analysis Experiment on the Surveyor Lunar Missions". Jet Propulsion Laboratory Technical Report 52-1265, pp. 505-82, June 15, 1968.

[3] Patterson, J.H, A. L. Turkevich and E. J. Franzgrote, Chemical analysis of surfaces using alpha particles, J. Geophys.Res., 70, 1311, 1965.

[4] Thanasis E. Economou, Anthony L. Turkevich, Keneth P. Sowinski, James H. Patterson and Ernest J. Franzgrote, The Alpha-Scattering Technique of Chemical Analysis, J. Geophys. Res., 75, No 32, 6514, 1970.

[5] Thanasis E. Economou,Anthony L. Turkevich and James H. Patterson, An Alpha Particle Experiment for Chemical Analysis of the Martian Surface and Atmosphere, J. Geophys. Res., 78, No 5, 781, 1973.

[6] Patterson, J.H, Ernest J. Franzgrote,A. L. Turkevich, W.A. Anderson, T.E. Economou, H.E. Griffin, S.L. Groach and K.P. Sowinski, Alpha Scattering Experiment on Surveyor 7: Comparison with Surveyor 5 and 6, J. Geophys. Res., 74, 6120, 1969.

[7] James H. Patterson, Harry E. Griffin, E. Philip Horwitz, and Carol A. Bloomquist, Preparation of High Level Alpha-Particle Sources for the Surveyor Alpha Scattering Experiment, Nuclear Technology, Vol. 18, 277-285, 1073.

[8] Thanasis E. Economou and Anthony L. Turkevich. "An Alpha Particle Instrument with Alpha, Proton and X-ray Modes for Planetary Chemical Analyses". Nucl. Instr. \& Methods 134, 1976, p. 391-399.

[9] Hovestadt, D., et al., PHOBOS, Proceedings of the International Workshop, Moscow, 1986, p 302

[10] Economou, T.E, J.S. Iwanczyk and R. Rieder, $\mathrm{A} \mathrm{HgI}_{2} \mathrm{X}$-ray Instrument for the Soviet Mars '94 Mission, Nucl. Instr. \& Methods A322,633-638, 1992.

[11] Linkin, V., et al., "A Sophisticated Lander for Scientific Exploration of Mars : Scientific Objective and Implementation", Planetary Space Science Journal, Vol. 46, Issues 6-7, 1998, pp 717-737.

[12] Rieder, R., H. Wänke, T. Economou and A. Turkevich; "Determination of the Chemical Composition of Martian Soil and Rocks: The Alpha-Proton-X-Ray Spectrometer", J. Geophys. Res. 1997 pp. 4027-4044.

[13] Rieder, R., T. Economou, J. Brückner, G. Dreibus, H. Wänke and A. Turkevich, First Elemental Analysis of Martian Surface by the Mobile Alpha Proton X-ray Spectrometer Attached to Mars Pathfinder Rover Sojourner. Meteoretics and Planetary Science, Vol. 32, No. 4, A107, 1997.

[14] Rieder, R., T. Economou, H. Wänke, A. Turkevich, J. Crisp, J. Brückner, G. Dreibus,H.Y. McSween, Jr., The Chemical Composition of Martian Soil and Rocks Returned by the Mobile Alpha Proton X-ray Spectrometer: Preliminary Results from the X-ray Mode, Science Vol. 278, (1997)1771-1774. 
[15] C. Nicole Foley, Thanasis E. Economou and Robert N. Clayton, Final Chemical Results from the Mars Pathfinder Alpha Proton X-ray Spectrometer, J. Geoph. Res. Vol. 108, No 12, doi:10.1029/2003JE002019, 2003.

[16] Rieder, R., et al., J. Geophys. Res., 108(E12), doi:10.1029/2003JE 002150, 2003

[17] http://www.esa.int/esaMI/Rosetta

[18] Klingelhoefer, G., J. Geophys. Res., 108, p. 8067, 2003

[19] Clark,B.C., et al., J. Geophys. Res., 87, p.10059, 1982

[20] Beagle 2 mission to Mars in 2003, http://www.beagle2.com/index.htm

[21] V. Radchenko, B. Andreichikov, H. Wanke, V. Gavrilov, B. Korchuganov, R. Rieder, M Ryabinin, and T. Economou, Curium-244 alpha-sources for space applications, Applied Radiation and Isotopes, 2000 Oct., 53(4-5):821-824.

[22] Economou, T.E, The Chemical Composition of an Asteroid Surface by the Alpha X-Ray Spectrometer on the MUSES-C Mission Lander, In Lunar and Planetary Science XXXI, 2000, 1861.pdf 


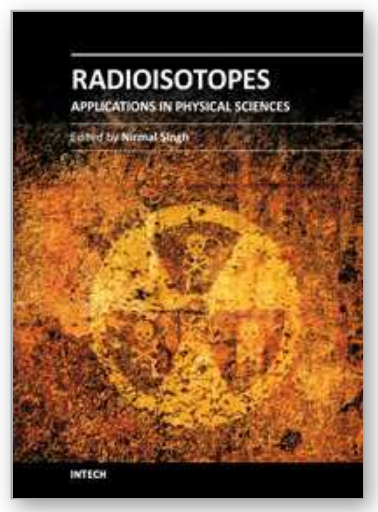

\author{
Radioisotopes - Applications in Physical Sciences \\ Edited by Prof. Nirmal Singh
}

ISBN 978-953-307-510-5

Hard cover, 496 pages

Publisher InTech

Published online 19, October, 2011

Published in print edition October, 2011

The book Radioisotopes - Applications in Physical Sciences is divided into three sections namely:

Radioisotopes and Some Physical Aspects, Radioisotopes in Environment and Radioisotopes in Power System Space Applications. Section I contains nine chapters on radioisotopes and production and their various applications in some physical and chemical processes. In Section II, ten chapters on the applications of radioisotopes in environment have been added. The interesting articles related to soil, water, environmental dosimetry/tracer and composition analyzer etc. are worth reading. Section III has three chapters on the use of radioisotopes in power systems which generate electrical power by converting heat released from the nuclear decay of radioactive isotopes. The system has to be flown in space for space exploration and radioisotopes can be a good alternative for heat-to-electrical energy conversion. The reader will very much benefit from the chapters presented in this section.

\title{
How to reference
}

In order to correctly reference this scholarly work, feel free to copy and paste the following:

Thanasis E. Economou (2011). History of Applications of Radioactive Sources in Analytical Instruments for Planetary Exploration, Radioisotopes - Applications in Physical Sciences, Prof. Nirmal Singh (Ed.), ISBN: 978953-307-510-5, InTech, Available from: http://www.intechopen.com/books/radioisotopes-applications-inphysical-sciences/history-of-applications-of-radioactive-sources-in-analytical-instruments-for-planetaryexploration

\section{INTECH}

open science | open minds

\section{InTech Europe}

University Campus STeP Ri

Slavka Krautzeka 83/A

51000 Rijeka, Croatia

Phone: +385 (51) 770447

Fax: +385 (51) 686166

www.intechopen.com

\section{InTech China}

Unit 405, Office Block, Hotel Equatorial Shanghai

No.65, Yan An Road (West), Shanghai, 200040, China

中国上海市延安西路65号上海国际贵都大饭店办公楼405单元

Phone: +86-21-62489820

Fax: $+86-21-62489821$ 
(C) 2011 The Author(s). Licensee IntechOpen. This is an open access article distributed under the terms of the Creative Commons Attribution 3.0 License, which permits unrestricted use, distribution, and reproduction in any medium, provided the original work is properly cited. 